\title{
Unloading Phenomena Characteristics in Brittle Rock Masses by A Large- Scale Excavation in Dam Foundation
}

\author{
Changgen Yan*, Tong Yuan and Kai Wang \\ Highway College of Chang'an University, Xi'an, Shaanxi Province P.R.China
}

\begin{abstract}
Xiaowan Hydropower station's dam located in south west of China is the second highest arch dam in the world $(\mathrm{h}=292 \mathrm{~m})$, its foundation is based on brittle rocks of biotite granite gneiss and amphibolites plagioclase gneiss. A largescale excavation around the foundation of the dam was conducted, near to 90 meters horizontal depth excavation and 130 meters vertical depth excavation, so the foundation dam was marked by a significant deformation and a severe damage near the excavation zone, namely excavation distributed zone (EDZ). This damage was caused by the unloading process. According to the in situ investigation, the characteristics of unloading rock masses were described. With the acoustic wave velocity monitoring method, the unloading rock masses characteristics of time effect and space distribution are summarized. Usually the unloading process causes fractures in rock masses along two perpendicular directions in the plane of the bank slope, one is parallel to the dam base slope, and the other is parallel to the river with steep-dip angle. Near to the excavation surface, the excavation damage are more serious, and from the high elevation area to low elevation area, the damage caused by unloading are becoming stronger and stronger, and the bottom of dam base is most damaged. The unloading deformation has a direct temporal dependence; in general, after the excavation, the unloading deformation increases quickly during the firsts 90 days, and increase by a slow rate from 90 to 180 days and after that the unloading deformation will be small enough to be neglected.
\end{abstract}

Keywords: Brittle rock masses, unloading characteristics, unloading temporal dependence, xiaowan hydropower station.

\section{INTRODUCTION}

Due to the weight of overlying materials or other load on the rock masses, the compression deformation or shear deformation would be changed in rock mass to keep the stress balance. As the river village cut down or being excavated, rebound deformation will happen in the rock masses near to the surface to adapt to the stress redistribution. As we have known, the weathering rock masses surface should be cleared before the dam built, and this unloading course is faster than the geological unloading process such as the cutting of the river valley, and the unloading deformation phenomena caused by the excavation is also marked faster and stronger than the natural process. The unloading rock masses are disturbed or damaged and its physical, mechanical and hydraulic properties are greatly changed [1], especially the area namely excavation disturbed zone (EDZ). The EDZ significantly affects the overall performance of these constructions and has become a key issue in the project design and construction, so much attention has been paid to the study of the EDZ all over the world. Quantification of the damage degree and the extent of the EDZ around underground opening have been studied using a micromechanics model according to the acoustic

\footnotetext{
*Address correspondence to this author at the Department of Geotechnique and Tunneling engineering, Highway College of Chang'an University, Xi'an, Shaanxi Province, P.R. China; Tel: 86-29-62630052;

Fax: 86-29-62630052; E-mail: yanchanggen@ 163.com
}

emission and microseismic events [2]. Some researchers adopted the displacement monitoring, plate loading and seismic tests, crosshole acoustic and seismic wave penetration testing and borehole deformation testing to estimate the EDZ in the slopes of the Three Gorges Project, China [3]. Another researchers adopted in-situ experiments to study the EDZ [4]. Many other countries such as Sweden, Switzerland, Germany and Japan are also studying the correlative problems about EDZ [5-7]. But how to quantitatively determine the extent and the damage degree of the EDZ is still a challenge up to now.

\section{PROJECT INTRODUCTION}

Xiaowan hydropower station is located in the middle stretches of Lancangjiang River, south west of China (Fig. 1). The dam is constructed on the V-shape valley whose both banks are very thick, steep and higher more than 1000 meters. The dam is the second highest building arch dam in the world ( $h=292 \mathrm{~m}$ ) (Fig. 2). Rock masses of the dam foundation including two kinds of brittle and hard rocks are biotite granite gneiss and amphibolites plagioclase gneiss. According to the uniaxial compressive test results, its compression strength is between 127.2 and 171.6 MPa. The test of crustal stress results show that the maximum in situ crustal stress is between 22 and $57 \mathrm{MPa}$, and it appeared under the bottom of river 40-57 m. In the borehole depth of $85 \mathrm{~m}$ disk-like rock cores appeared, so the stress in the rock should be considerable high. 
The excavation situation of Xiaowan dam foundation is shown as Fig. (2). According to the design of dam foundation, the vertical cutting depth of two banks are more than $30 \mathrm{~m}$ in general, and the maximum vertical cutting depth is about $90 \mathrm{~m}$ and maximum horizontal cutting depth is about $130 \mathrm{~m}$ (Fig. 3). Such large-excavation can lead to the stress changed about 0.8-2.4 MPa in theory, but it caused

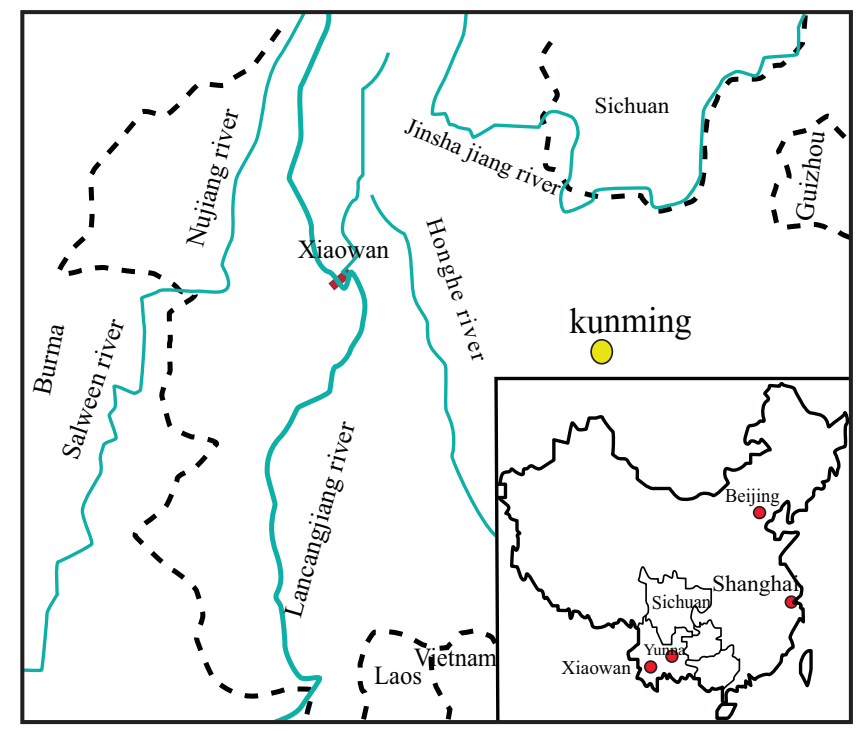

Fig. (1). Xiaowan hydropower station location diagram.

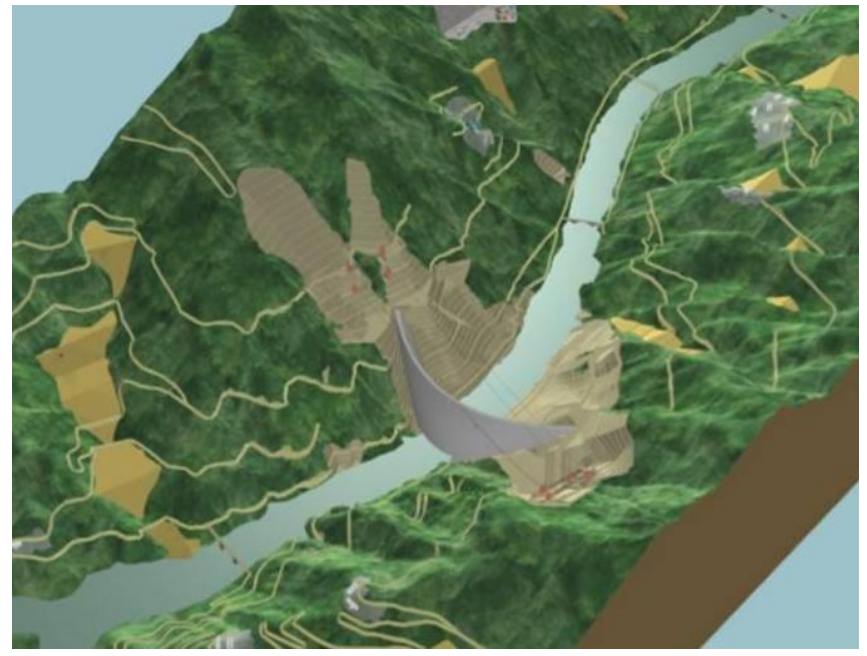

Fig. (2). Excavation three-dimensional sketch of Xiaowan hydropower station.

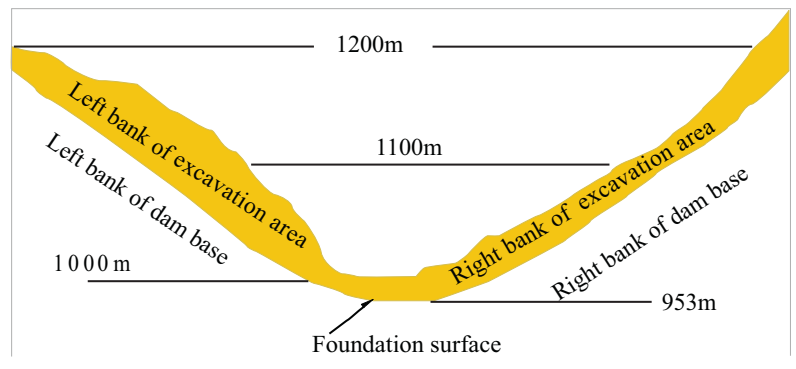

Fig. (3). Sketch map of the excavated section of the dam foundation. a marked deformation and even broken on the strength near to $100 \mathrm{MPa}$ hard rocks.

\section{UNLOADING CHARACTERISTICS OF DAM BASE ROCK MASSES}

There are four kinds of unloading deformations near to the surface of dam foundation after excavation, and they will be introduced one by one.

\section{Unloading Fractures Along the Structures with Gentle Dip Angles}

There are two kinds of unloading fractures along the structures with low dip angles. The first one is the unloading fractures growth with sheet like fractures (Fig. (4a)), and the fractures' thickness are from $0.5 \mathrm{~cm}$ to $5 \mathrm{~cm}$, most of the unloading fractures appeared on the shallow of the dam foundation. The second one is the unloading fractures opened widely, and some small broken rock fragments remained in the opened cracks (Fig. (4b)), in general, the unloading fractures are no more than $5 \mathrm{~m}$ depth.

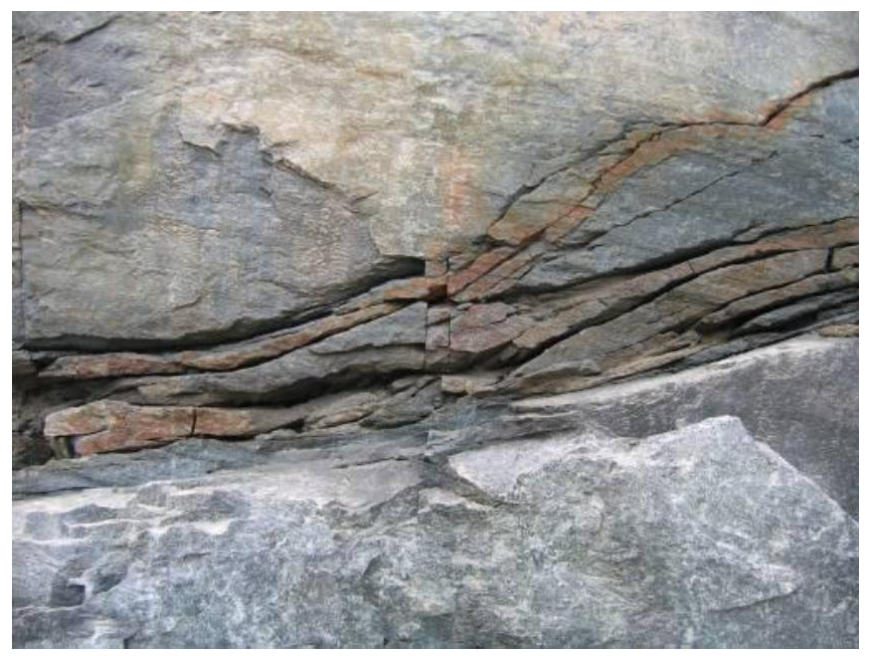

(a) Amphibolites plagioclase gneiss.

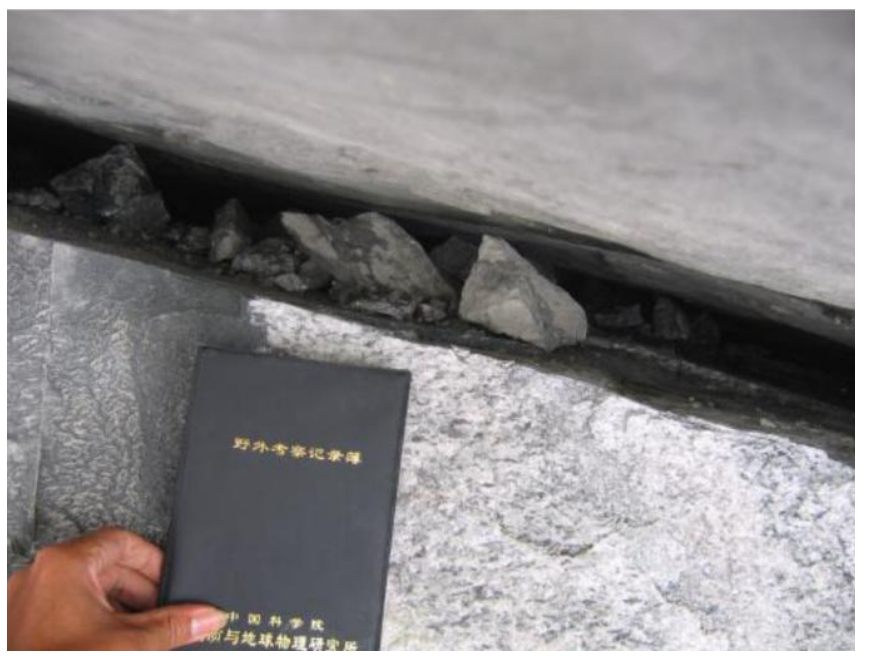

(b) Biotite granite gneiss.

Fig. (4). Unloading fractures in different hard rock mass. 
From the Fig (4), the characteristics of unloading fractures are apparently different in different rocks. In amphibolite plagioclase gneiss rock, the unloading fractures are thin sheet, sheet-like, about $0.2 \sim 3 \mathrm{~cm}$ thickness, generally, developed as a series of unloading fractures, and the widen of fractures zone near to $50 \mathrm{~cm}$ (see Fig. (4a)); while in biotite granite gneiss, the unloading fractures are narrow, straight and opening so widely near to $5-10 \mathrm{~cm}$, many broken rocks in the opening cracks.

\section{Unloading Fractures Along the Structures with Dip High Angles}

There are two groups of structures with steep dip angle. One structure strikes east-west, and the other structure strikes south-north which along the river. The unloading fractures are mostly controlled by structures and they can be manifested in two aspects. Firstly, the unloading fractures are interrupted when encountered the structures with steep dip angles; secondly, if there have some space for deformation, the unloading fractures will open along the structures which strikes to $\mathrm{SN}$ with steep dip angles and

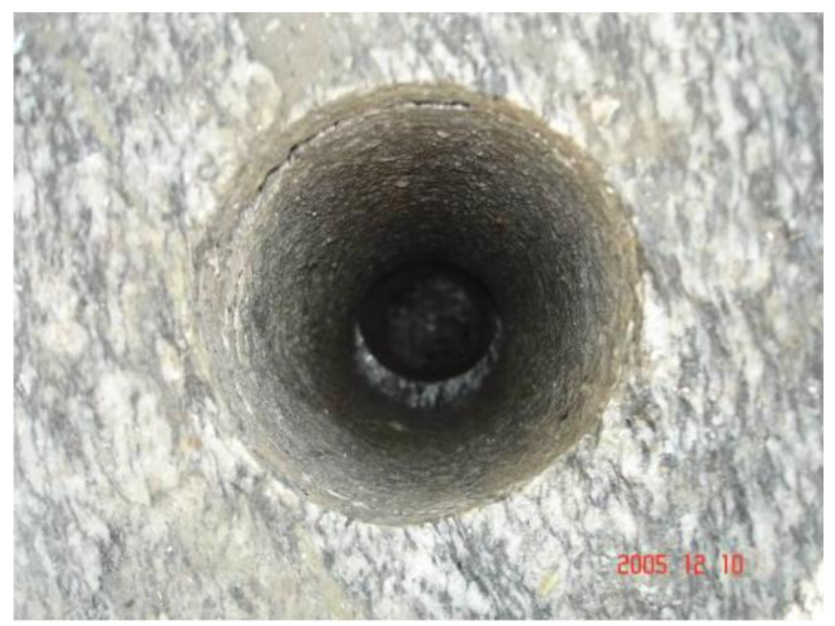

Fig. (5). Bored internal dislocation.

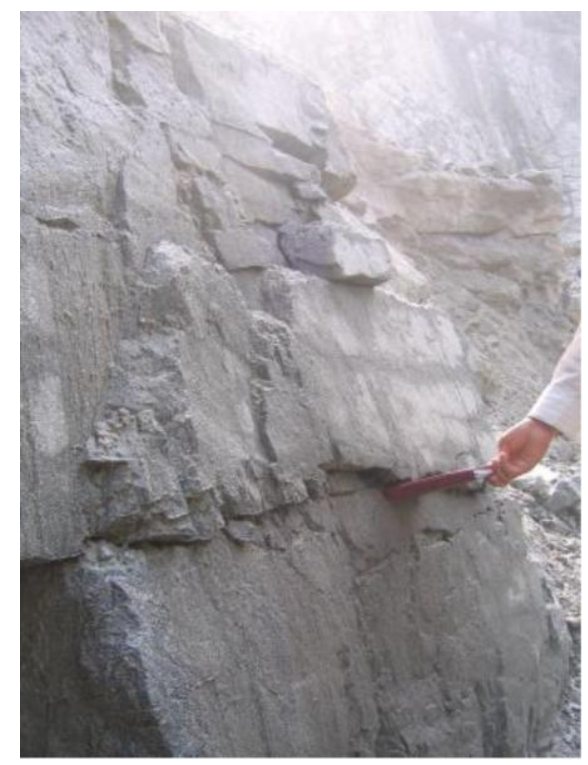

Fig. (6). Steep rock wall disloction. shearing along the structure which strikes to river with low dip angles see Figs. (5 and 6). Due to unloading, the cracks can rebound and in a way as shearing along low dip angle structure and tension along steep angle structure. Usually, the opening is apparently in the zone approaching to the excavation surface and decrease along with the depth (Fig. 7).

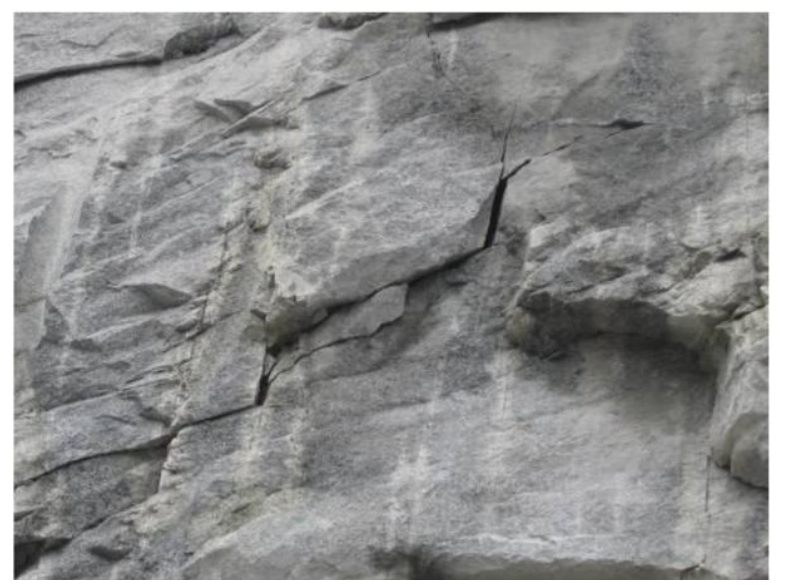

Fig. (7). Shearing along low-dip angle crack and tension along steep-angle crack.

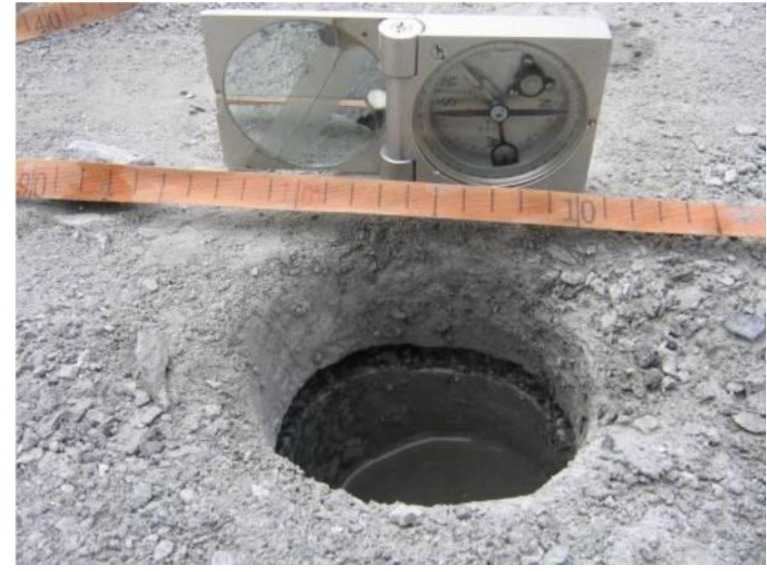

(a) New fracture in drilling hole

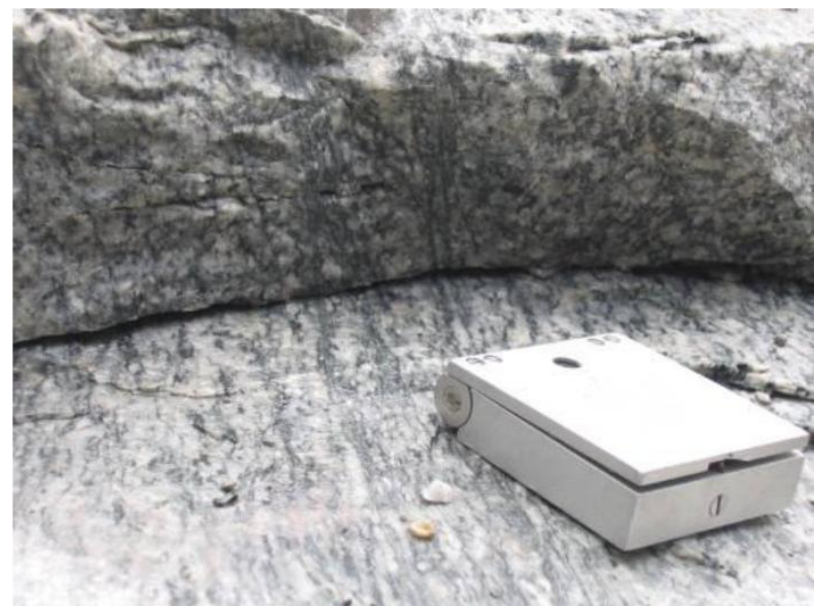

(b) New fracture in low elevation dam session.

Fig. (8). New fractures in intact rock. 


\section{New Cracks Opening Along with the Hidden Cracks in the Zone Approaching the Excavation Surface}

Usually, the low-angle cracks appear as discontinuous closed micro-cracks before excavation, while the foundation being excavated, the rock rebounded and caused deformation along with the cracks being stress redistributed, then the discontinued micro-cracks were mostly coherent as a macro fracture which opened near to $20 \mathrm{~mm}$. Fig (8) shows the excavation damage zone situation at the bottom foundation of left bank (Level $954 \mathrm{~m}$ ). it has been found that the most roughness direction of the unloading fractures were dipping to the river (Fig. 9).

\section{Rock Burst}

In addition to the above mentioned moderate unloading deformation, there is also very severe destroyed mode, namely rock burst. The stress is concentrated in the area of the valley at the bottom of the river bed due to the topography, and the rock burst were seen at this place after dam base excavation, it has been found that the rock burst remains at the right bank of the foundation surface elevation 962 m (see Fig. 10).

\section{Unloading Fractures Distributed with the Space}

There are three characteristics of unloading fractures along with space.

The first characteristic of unloading fracture is that the low-dip fracture is parallel to the slope of construction excavation surface, and the angle also varied with the excavation surface. The second one is that the low-dip angle unloading fractures are tending to each other and tending to the valley, shown in Fig. (11). The last one is that the unloading fractures are often subjected to in the control of steep-dip angle and low-dip angle fractures in the highelevation area, and the destroyed surface appears ladder-like or ring-shear sharp (Fig. 12), it is shearing along with the structure surface, while in the low-elevation area, the destroyed surface are subject to in the control of the low-dip angle structural surfaces and mostly rebounded like-slab due to the stress concentration, shown in Fig. (13).

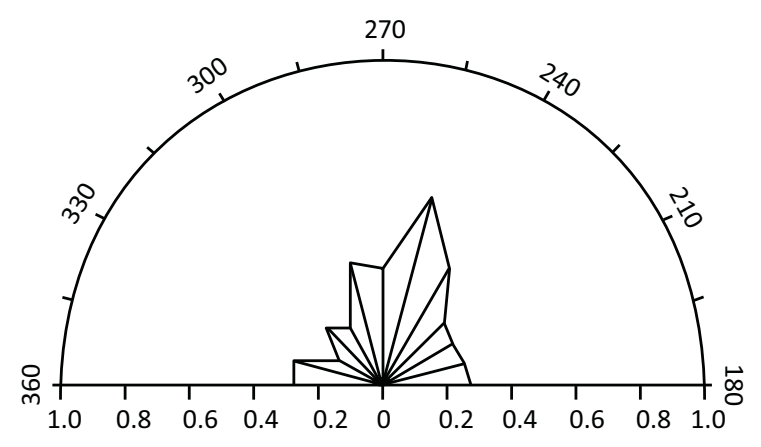

(a) Left bank

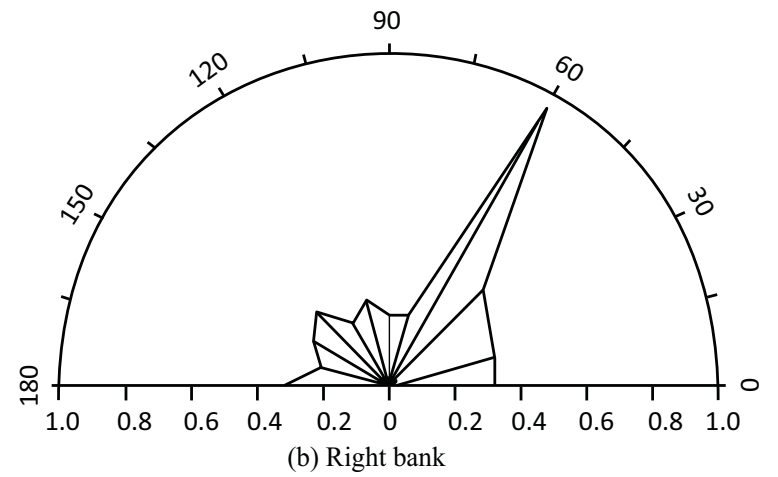

Fig. (9). Joint surface roughness coefficient anisotropy properties of low-angle joints.

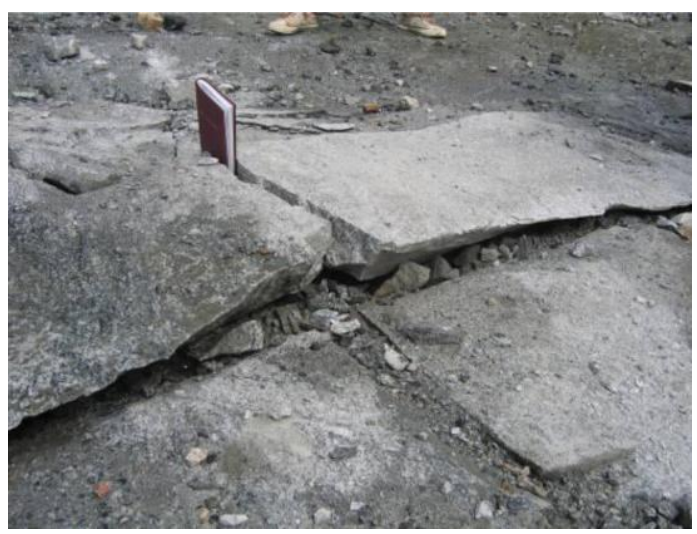

Fig. (10). Arciform broken-off by rock burst.

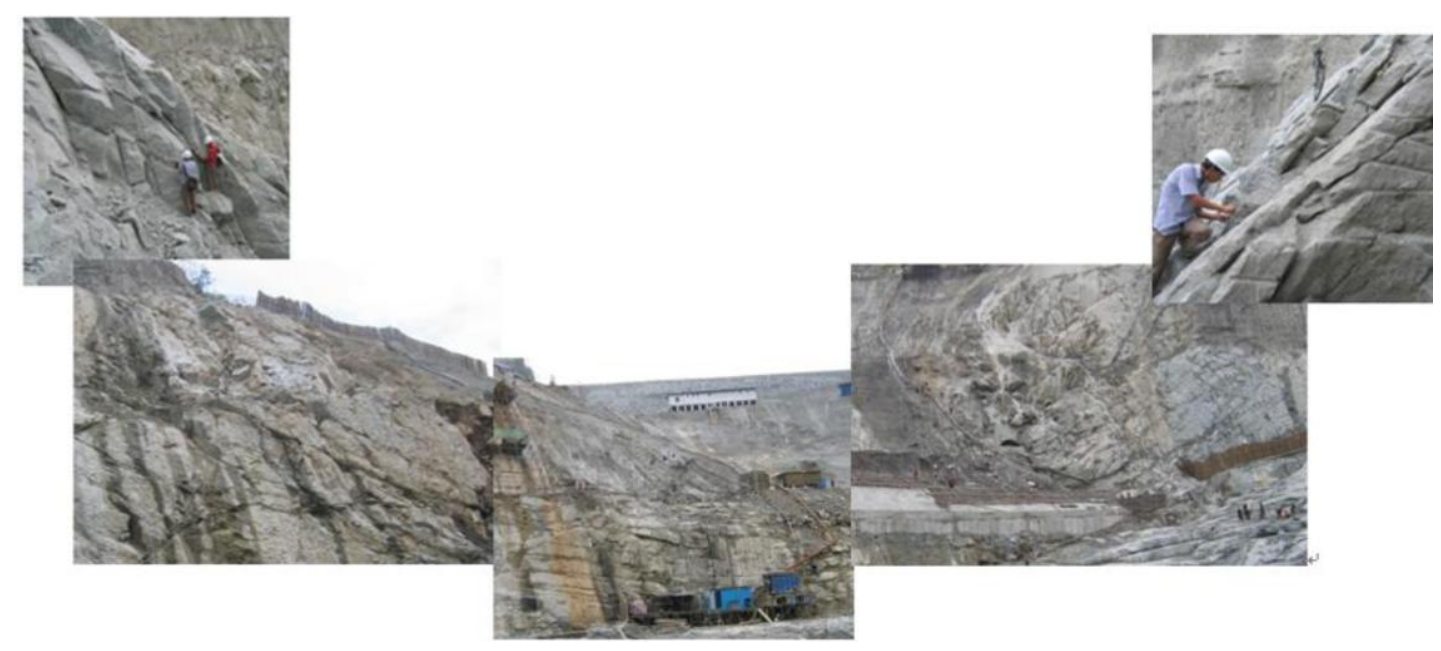

Fig. (11). Dip-angles of unloading fractures varied with the excavation surface of dam base. 


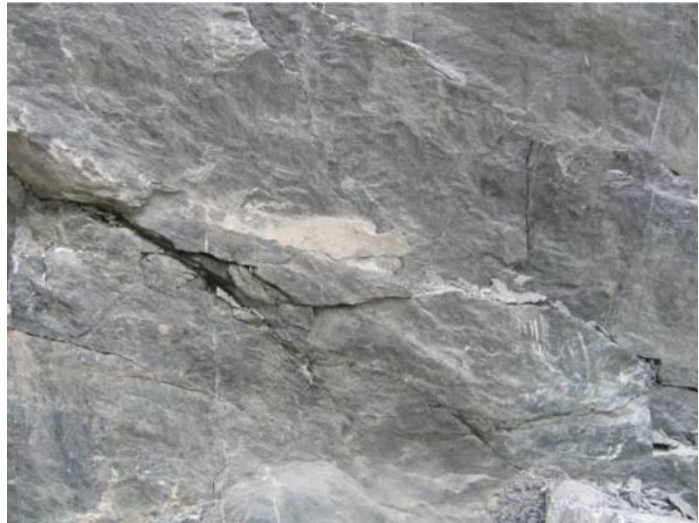

Fig. (12). Fractures like diamond ring shape.

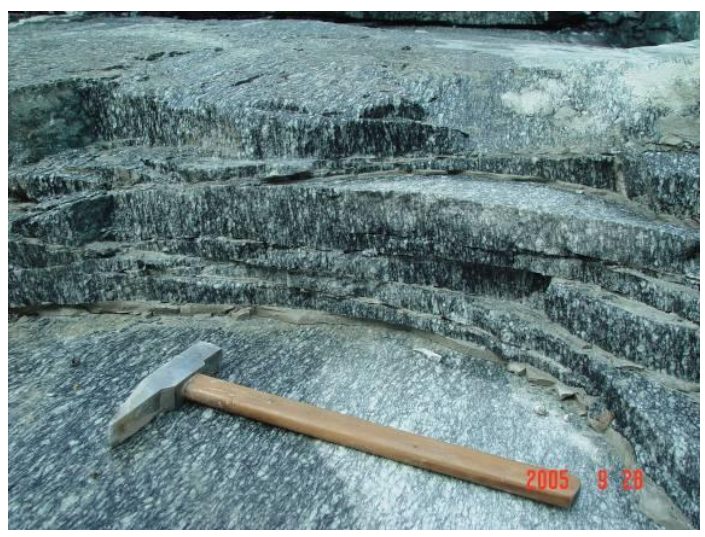

Fig. (13). Thin-tabulate fractures.

\section{Unloading Vary with Time and Depth}

Through continuous monitoring the acoustic wave velocity of rock mass in boreholes on the dam base, the

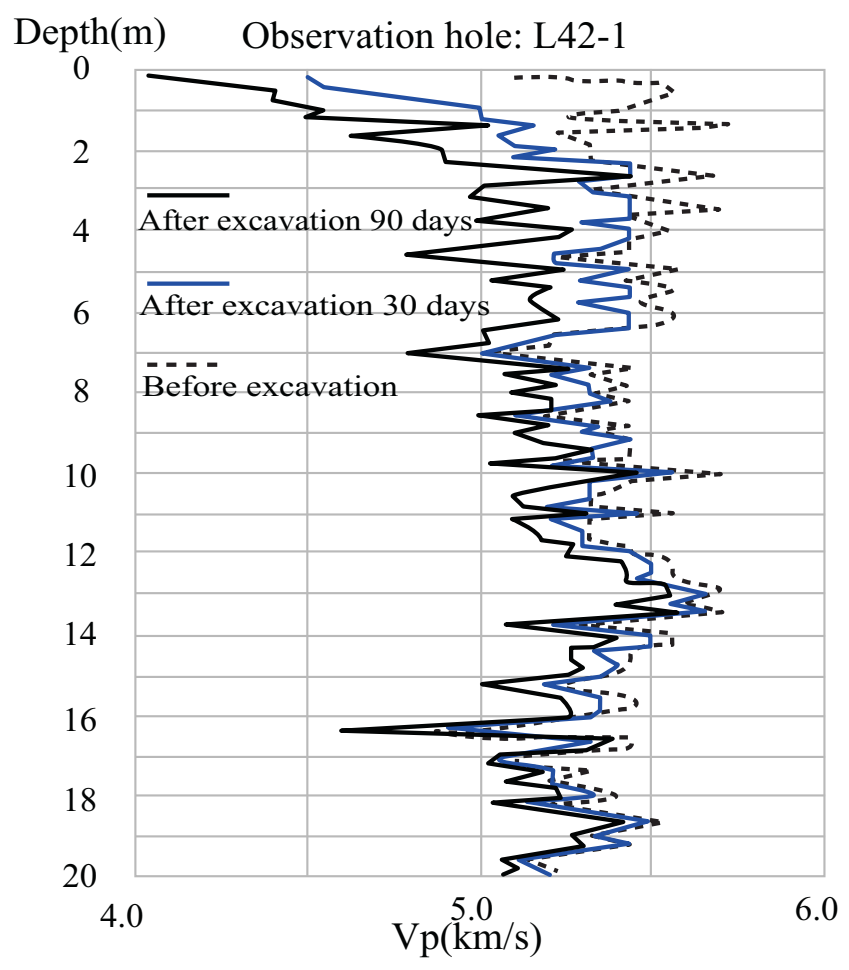

Fig. (14). Evolution of acoustic wave velocity vs. depth in observation borehole.

regular of unloading rock masses varied with time and depth can be revealed. The Fig. (14) shows the curves of unloading factures varied with time and depth after excavation and the Fig. (15) shows the acoustic wave velocity change rate varied with time after excavation from 15 days to more than 270 days. The curves show that rock acoustic wave velocity changes small with the depth increasing, and over a certain

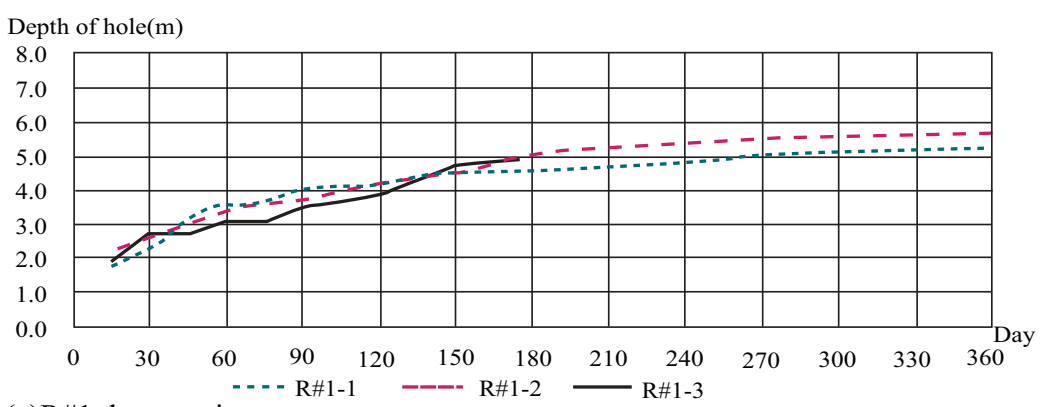

(a)R\#1 dam session

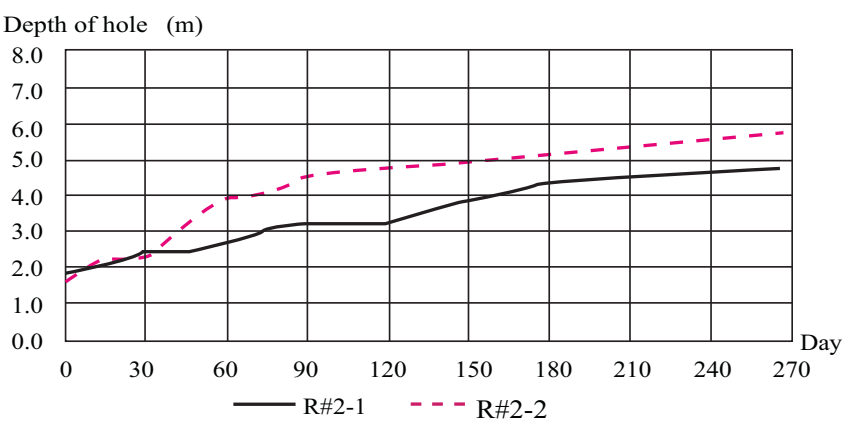

(b)R\#2 dam session

Fig. (15). The rate of change over $5 \%$ of acoustic wave velocity after-excavation $v s$. post-excavation. 
depth, there are a significant reduction of the rate of acoustic wave velocity. The result shows that the unloading deformation has a direct temporal dependence; in general, after the excavation, the unloading deformation increases quickly during the firsts 90 days, and increase by a slow rate from 90 to 180 days and after that the unloading deformation will be small enough to be neglected.

\section{CONCLUSION}

Through comprehensive conducting investigation, describing the unloading characteristics in field and continuous acoustic wave velocity monitoring the boreholes on the dam base, some instructive conclusions are gained.

The unloading fractures are mostly developed along with the original structures, and shearing deformation along with the low-dip angle structure and tension deformation along with the steep-dip angle structure. In low-elevation area, the unloading cracks appeared straight slab-like. In the space distributions, the unloading deformations in low-elevation area are more obvious than high-elevation area, and the unloading deformation are weaker with the depth increasing. In time effecting, the unloading deformation increases quickly during the firsts 90 days, and increase by a slow rate from 90 to 180 days and after that the unloading deformation will be small enough to be neglected. Anyway, all the deformation of unloading characteristics of rock masses is subjected to the stress redistribution.

\section{CONFLICTS OF INTEREST}

The authors confirm that this article content has no conflict of interest.

\section{ACKNOWLEDGEMENTS}

The research reported in this paper was partially sponsored by the National Natural Science Foundation of China (Grant No. 41272285) and by the Fundamental Research Funds for the Central Universities of China (Grant No. 2013G2211003). I would like to thank professor Faquan $\mathrm{Wu}$ and Professor Shengwen Qi to give the chance to take part in the project of investigation the geology situation of Xiaowan hydropower dam foundation. The opinion and analysis presented in this paper are those of the authors.

\section{REFERENCES}

[1] L. Malmgren, D. Saiang, J. Toyra and A. Bodare. "The excavation disturbed zone (EDZ) at Kiirunavaara mine, Sweden - by seismic measurements", J. App. Geophys., vol. 61, pp. 1-15, January 2007.

[2] M. Cai and P. K. Kaiser. "Assessment of excavation damaged zone using a micromechanics model", Tunnel. Undergr. Space Tech., vol.20, pp. 301-310, July 2005.

[3] Q. Sheng, Z. Q. Yue, C. F. Lee, L. G. Tham and H. Zhou, "Estimation the excavation disturbed zone in the permanent shiplock slopes of the Three Gorges Project, China". Int. J. Rock Mech. Mining Sci., vol. 39, pp. 165-184, Feb 2002.

[4] T. Sato, T. Kikuchi and K. Sugihara, "In-situ experiments on an excavation disturbed zone induced by mechanical excavation in Neogene sedimentary rock at Tono mine, central Japan". Eng Geo., vol. 56, pp. 97-108, Jan 2000.

[5] K. Schuster, H-J. Alheid and D. Böddener, "Seismic investigation of the Excavation damaged zone in opalinus clay", Eng. Geo., vol. 61, pp. 189-197, June 2001.

[6] S. Kruschwitz and U. Yaramanci, "Detection and characterization of the disturbed rock zone in claystone with the complex resistivity method". J. Appl. Geophys., vol. 57, pp. 63-79, Jan 2004.

[7] P. Blumling, F. Bernierb, P. Lebonc and C. D. Martin, "The excavation damaged zone in clay formations time dependent behaviour and influence on performance assessment". Phys. Chem. Earth, vol. 32, pp. 588-599, Nov 2007. 